\title{
El Generalife y las ruinas árabes de sus contornos. Un capítulo inédito de los Nuevos Paseos de Simón de Argote
}

\author{
The Generalife and the Arabian Ruins of \\ its Surroundings. An Unknown Chapter of \\ the Nuevos paseos by Simón de Argote
}

\author{
Juan Manuel Barrios Rozúa \\ Universidad de Granada
}

Los Nuevos paseos (1806-1807) de Simón de Argote constituyen una de las obras más notables escritas sobre la Alhambra y suponen una respuesta ilustrada a las tergiversaciones sobre el pasado romano de Granada del clérigo y arabista Velázquez de Echeverría. Desgraciadamente la obra quedó incompleta porque no llegó a cumplir su objetivo de abarcar las «antigüedades árabes» ubicadas fuera de la ciudadela nazarí. En este artículo se presenta, con anotaciones críticas, un capítulo inédito dedicado al Generalife y a las ruinas de su entorno, el cual fue entregado por su autor al rey José Bonaparte durante su estancia en Granada y se conservó entre los papeles perdidos por el monarca en la batalla de Vitoria. A partir de documentación hallada en muy diversos archivos y publicaciones de la época se arroja luz sobre la mal conocida trayectoria de Simón de Argote y se profundiza en su relación con el general Horace Sebastiani, militar que por orden de Napoleón realizó labores de embajador en Estambul y en otras ciudades de Próximo Oriente, antes de gobernar el Reino de Granada.

Palabras clave: Historiografía; Granada nazarí; arquitectura; arqueología; orientalismo; Guerra de la Independencia.
Simón de Argote's Nuevos paseos (1806$1807)$ is one of the most remarkable works written on the Alhambra. It offers an Enlightenment response to the distortions of the Roman past of Granada of the cleric and Arabist Velázquez de Echeverría. Unfortunately, the work was unfinished because it did not cover all the «Arabian antiques» located outside the Nassrid city. In this article, an unknown chapter about the Generalife and the ruins around is presented, accompanied with critical notes. It was given by the author to King Joseph Bonaparte during his stay in Granada and it was kept among the papers the king had lost at the Battle of Vitoria. The study of the documents found in different archives and publications of that time sheds some light on the mysterious personality of Simón de Argote and deepens in the knowledge of his relationship with General Horace Sebastiani, a military who was embassador in Istanbul and other cities of the Middle East under Napoleon's order, before he ruled the Kingdom of Granada.

Key words: Historiography; Nasrid Granada; Architecture; Archeology; Orientalism; Peninsular War. 


\section{Simón de Argote y el orientalismo de los invasores franceses}

El 26 de abril de 1806 la Gazeta de Madrid anunciaba la publicación de dos volúmenes de los Nuevos paseos históricos, artísticos, económico-políticos, por Granada y sus contornos. Estos dos volúmenes recogían sólo la Alhambra, monumento que «ha excitado la curiosidad de los viageros inteligentes», a decir del anuncio de la Gazeta ${ }^{1}$. Constituían el comienzo de una amplia obra que debía abarcar toda la ciudad de Granada. Años después se publicó, como luego veremos, un tercer volumen que completaba la descripción de la Alhambra, y nunca llegaron a ver la luz los prometidos tomos que abordarían el resto de la ciudad.

El autor era Simón de Argote, doctor en jurisprudencia, caballero síndico, miembro de la Sociedad Económica de Amigos del País y hombre que gozaba de una buena posición económica, como ponen de manifiesto la contribución que pagó al Estado en el año 1801 o la posesión de un carmen junto al Darro, el cual era famoso por sus parras. El botánico Simón de Rojas Clemente y Rubio, que lo trató personalmente, destaca su erudición en economía, filosofía e incluso mineralogía, así como su «finísimo gusto, mucho talento, travesura, actividad y exquisitos conocimientos en las Bellas Letras», destacando que «su carácter es el de la Filosofía» ${ }^{2}$. Incluso probó suerte en el terreno de la salubridad urbana con un estudio sobre cómo prevenir la peste en las ciudades redactado cuando la fiebre amarilla hacía estragos ${ }^{3}$.

Los Nuevos paseos constituyeron un salto cualitativo en la historiografía sobre la Alhambra, de la cual se habían realizado descripciones generalmente breves y fragmentarias desde el siglo XVI, y superaban con creces al más ambicioso trabajo hasta entonces publicado, con el

${ }^{1}$ Gazeta de Madrid, 26 abril 1808.

2 Simón de Argote aparece entre las personas acaudaladas de la ciudad en la contribución que el Estado impuso a todo el país para hacer frente a unos gastos cada vez más elevados por los esfuerzos bélicos. Como caballero síndico lo he visto citado en 1808 (Archivo Histórico Municipal de Granada, en adelante AHMG, legajo 302-3 y Actas Capitulares, 27-30 enero y 1 febrero 1801). Para una valoración de sus saberes véase Clemente y Rubio, Ensayo sobre las variedades de la vid común que vegetan en Andalucía, con un índice etimológico y tres listas de plantas en las que se caracterizan varias especies nuevas, y Clemente y Rubio, Viaje a Andalucía. Historia natural del reino de Granada (18041809), p. 199.

${ }^{3}$ El trabajo lo escribió junto a Antonio y Juan Bautista Soldevilla en 1800 y se titulaba Origen de la peste y policía médica para extinguirla y precaverla, pero obtuvo un dictamen negativo de la Academia de Medicina. 
cual rivalizaban abiertamente, los Paseos por Granada y sus contornos (1764-1767) de Juan Velázquez de Echeverría. Sin embargo, la prometedora trayectoria de Simón de Argote se iba a ver truncada por la Guerra de la Independencia, pues su afrancesamiento le empujó hacia el bando que, tras iniciales triunfos, iba a ser finalmente derrotado.

En enero de 1810 los franceses ocupaban Andalucía en una arrolladora expedición. El día 28 entraban en Granada sin encontrar resistencia y hacían ondear la bandera francesa en la Alhambra. Los comandaba el general Horace-François-Bastien Sebastiani de la Porta, el militar del estado mayor de Napoleón que había tenido una relación más estrecha con el mundo musulmán, la cual iba a reverdecer al conocer la Alhambra y el Generalife. En octubre de 1801 Napoleón le había encomendado la misión de ganarse el respaldo del Imperio otomano frente a Inglaterra y Rusia. En Estambul hizo entrega a Selim III de una carta de Napoleón y, en tanto recibía una respuesta, permaneció tres semanas visitando la ciudad, de la que supo apreciar su belleza oriental, aunque quedó sorprendido por la anarquía administrativa del decadente Imperio otomano. La respuesta de Selim III fue positiva y Napoleón, satisfecho por sus gestiones, lo envió en misión diplomática a Trípoli, Egipto y Siria, donde continuará familiarizándose con las ciudades y la arquitectura musulmanas ${ }^{4}$. De vuelta a Europa participa en algunas batallas hasta que es nombrado embajador en Estambul, un puesto que equivale al de cónsul general de Francia en todo el Levante, y de nuevo parte para la capital otomana con la misión de fortalecer la alianza franco-otomana frente a Rusia. Llega allí el 10 de agosto de 1806 y es acogido con gran pompa en el palacio de Selim III. Cuando lleva un mes de estancia tiene la ocasión de conocer a René de Chateaubriand, que está realizando una etapa de su largo viaje hacia Jerusalén. Sebastiani literalmente lo abruma con su hospitalidad y le sirve de guía por la ciudad mostrándole los edificios más importantes. No sería de extrañar que el militar, en el ambiente oriental de Estambul, se contagiara de los planteamientos románticos del escritor, el cual lo describe como una persona de carácter sensible ${ }^{5}$. Sebastiani hubo de abandonar la capital otomana cuando una rebelión contra Selim III lo dejó en una

${ }^{4}$ Mesmay, Horace Sébastiani, soldat, diplomate, homme d'Etat, maréchal de France, pp. 44-50.

${ }^{5}$ El escritor mostrará su gratitud hacia el general en su célebre viaje a Próximo Oriente; Chateaubriand, Itinéraire de Paris à Jérusalem, pp. 258-260. 
complicada posición. Tras dieciocho meses de misión diplomática regresa en julio de 1808 a su patria, justo en el momento en el que llegan las noticias de la derrota de Bailén.

Horace Sebastiani es trasladado a la Península Ibérica y participa con éxito en varias batallas antes de incorporarse a la expedición que invadió Andalucía. En el Reino de Granada se instaló con pompa y practicó un despotismo ilustrado y militarizado, hasta el punto de que sus detractores lo llamarían irónicamente «Sebastiani I rey de Granada $»^{6}$. Aunque Sebastiani iba a convertir la Alhambra en su bastión militar y a crear un área fortificada en su entorno, causando graves daños en las ruinas del castillo de Santa Elena y quién sabe qué otros vestigios arqueológicos, cuidó como luego veremos la Casa Real y el Generalife. Hasta tal punto quedó prendado de los palacios nazaríes que hizo colocar en ellos algunos muebles (almohadones, tapices, divanes) y pudo vérsele despachar en el salón de Embajadores sentado al modo oriental en cojines de satén rojo, o contemplar abstraído los patios y salas con sus sofisticadas ornamentaciones. No en vano se le ha llegado a comparar con el mariscal Lyautey «que hará una obra análoga en ese Marruecos pleno de recuerdos de la misma civilización»? ${ }^{7}$.

Horace Sebastiani se fijó inmediatamente en Simón de Argote, no sólo porque se ofreció gustoso a colaborar con las autoridades josefinas, sino también por su erudición. De hecho fue elegido para cribar los libros incautados en los conventos, separando la literatura devocional de los volúmenes que pudieran tener algún interés científico, histórico o literario. Mientras los libros escogidos tendrían como probable destino una biblioteca pública — parece que fueron almacenados provisionalmente en el convento de Santo Domingo-, los expurgados, la gran mayoría, fueron trasladados a la Alhambra para utilizar su papel en la fabricación de cartuchos ${ }^{8}$.

Simón de Argote vivió sus mejores días de afrancesado durante la visita del «rey intruso». José Bonaparte era persona de elevada cultura, con un interés siempre vivo por las novedades literarias, hasta el punto de recibir mensualmente cajas de libros procedentes de Francia y haber leído obras como Las mil y una noches y a autores como Florián o Cha-

${ }^{6}$ Bouillé, Souvenirs et fragments (1769-1812), p. 389.

Mesmay, Horace Sébastiani, pp. 91-92.

8 Valladar y Serrano, La invasión francesa en Granada (1810-1812), p. 50. 
teaubriand. Sabemos que mantenía correspondencia con Alexandre Laborde ${ }^{9}$, autor del Voyage pittoresque et historique de l'Espagne (1806), en cuyo segundo volumen se trataba con detalle y entusiasmo la Alhambra. Otra persona con la que el rey tenía estrecha relación y que debió de hablarle de manera encomiástica de la ciudad era su ministro Miguel José de Azanza, que formaba parte de la expedición real y que poseía una lujosa casa en la carrera del Darro ${ }^{10}$.

El convoy real llegó a Granada el 16 marzo de 1810 siendo objeto de una triunfal acogida. En la Alhambra y el Generalife se realizaron preparativos que incluyeron la limpieza de ambos palacios y la habilitación en cada uno de ellos de un departamento con muebles a la francesa a fin de que el monarca pudiera instalarse «algunos días, si esto le fuese agradable» ${ }^{11}$. El interés de José Bonaparte por la Alhambra lo señala el general Bigarré, quien nos dice que el rey fue varias veces al palacio de los reyes moros «donde todavía se ven tantos objetos curiosos que recuerdan las desgracias de los Abencerrajes y el triunfo de Fernando el Católico» ${ }^{12}$. La propia Gazeta de Madrid señala que «S. M. emplea el corto tiempo que le queda después de sus tareas en reconocer las antigüedades de esa ciudad y sus amenas cercanías» ${ }^{13}$. En alguno de esos paseos le acompañó sin duda Simón de Argote, el cual debió de entregar al rey no sólo los tomos que había publicado de sus Nuevos paseos por Granada y sus contornos, sino un capítulo inédito dedicado al Generalife, que el rey guardó entre sus papeles.

Es indudable que el Generalife despertó un especial interés en el rey, que ordenó que se trazaran jardines nuevos en él y se efectuaran obras de restauración (decreto del 20 de marzo de 1810). Estas obras

9 Esta correspondencia se conserva en Archives Nationales de France (en adelante ANF), $381 \mathrm{AP} / 27$.

${ }_{10} \mathrm{Su}$ casa la confiscó la junta patriótica para convertirla en colegio militar, pero la recuperó cuando Horace Sebastiani conquistó la ciudad; Archivo General Militar de Segovia, Sección $3^{\text {a }}$, División $3^{\text {a }}, 517$.

${ }_{11}$ AHMG, legajo 908-11 y Actas Capitulares 27 febrero 1810. El prisionero británico Blayney señala en noviembre de 1810 que hay algunas dependencias «decoradas a la francesa», aunque poco y con mal gusto: «un salon y un boudoir parisinos en un palacio de reyes moros, construido hace cinco siglos, es una cosa casi tan absurda como una estatua antigua vestida de petit-maître moderno»; Blayney, Relation d'un voyage forcé en Espagne et en France dans les années 1810 a 1814, p. 69. p. 274.

${ }^{12}$ Bigarré, Mémoires du General Bigarré, aide de camp du roi Joseph (1775-1813),

${ }^{13}$ Gazeta de Madrid, 8 abril 1810.

Al-Qanțara XXXV 1, 2014, pp. 29-59 ISSN 0211-3589 doi: 10.3989/alqantara.2014.002 
formaron parte de la campaña que se emprendió en la Casa Real de la Alhambra, justificada así por la Gazeta de Madrid: «Los viajeros que han reconocido la Alhambra, han lamentado el abandono y degradación en que se hallan los preciosos monumentos que en ella se encuentran, y que estaban amenazados de su total ruina» ${ }^{14}$. La supervisión de las obras se la encargó el monarca a Miot de Melito, superintendente de la Casa Real, pero como éste se marchó con el séquito real y las comunicaciones eran tan malas debido a la guerra, tampoco su nombramiento tuvo ninguna consecuencia práctica. Miot de Melito había leído Las Guerras civiles de Granada y al visitar la Alhambra en compañía del rey apuntó que el palacio refleja los días de esplendor de esa civilización en un momento en el que Europa «estaba hundida todavía en la ignorancia y la barbarie» ${ }^{15}$.

Quien verdaderamente acabó dirigiendo las obras de restauración de la Casa Real y el Generalife fue el general Horace Sebastiani el cual, el 2 de abril, advirtió a Francisco Aguilar (administrador del real patrimonio en Granada) que él mismo corregiría y enviaría al rey los planos de las obras ${ }^{16}$. No tenemos noticias de que esos planos fueran efectivamente realizados y las labores en la Casa Real y el Generalife se limitaron a seguir la tónica de las realizadas en el siglo XVIII, o sea, a que una cuadrilla de albañiles, carpinteros y herreros, dirigidos por el veterano maestro de obras Thomás López, realizara obras de consolidación, y a que unos jardineros locales renovaran la vegetación y trazaran nuevos parterres ${ }^{17}$.

Los franceses consideraron el Generalife como parte del patrimonio nacional e ignoraron por completo a los marqueses de Campotéjar, que detentaban la alcaidía del lugar desde el siglo XVI, aunque sus descendientes, emparentados con una familia italiana, residían en Italia y

${ }_{14}$ Gazeta de Madrid, 12 abril 1810.

15 Miot, Mémoires du Comte Miot de Mélito, Ancien Ministre, Ambassadeur, Conseiller d'État et Membre de l'Institut, pp. 128-130. Aunque la mayoría de los franceses que visitaron la Alhambra y el Generalife en estos años tienen palabras muy elogiosas para tan exóticos edificios, no faltó quien como Saint-Vincent afirmara: «Los jardines del Generalife, tan alabados, son inferiores a cualquier casa de campo del último burgués de París». Este autor estuvo en Granada hacia 1810, pero publicó la memoria de su viaje muchos años después; Saint-Vincent, Guide du Voyageur en Espagne, pp. 570-574.

16 Archivo General de Palacio, sección Reinados, Gobierno Intruso, legajo 19/11.

17 Archivo Histórico de la Alhambra, legajo 259-4 y AHMG, legajo 777-8 y Junta de Propios y Arbitrios, 19 diciembre 1812. 
nunca visitaban el lugar ${ }^{18}$. En él tenían un administrador que cuidaba del edificio y que les enviaba las rentas producidas por unas huertas arrendadas a campesinos ${ }^{19}$.

\section{La publicación del tercer volumen y el manuscrito del Generalife}

Cuando el 4 de diciembre de 1810 quedó vacante la prefectura de Jaén al caer enfermo quien la detentaba, el general Sebastiani quiso nombrar a Simón de Argote para el puesto. Un informante de José Bonaparte señalaría a Argote como uno de los protegidos del general, tachándolo de «creature» o paniaguado de Sebastiani, lo que quizás impidió su nombramiento en esa ciudad dado que el rey recelaba de la tendencia de sus jefes militares a convertirse en virreyes ${ }^{20}$. Sin embargo, más adelante Argote fue designado secretario general de la prefectura de Segovia, puesto en el que debió de permanecer poco tiempo antes de retornar a Granada ${ }^{21}$.

Durante estos convulsos años de guerra Argote logró entregar a la imprenta un tercer volumen de sus Nuevos paseos. Este volumen, muy

${ }^{18}$ En 1826 el Estado español inició un pleito contra esta familia, el cual se prolongó durante casi un siglo y acabó por confirmar la propiedad estatal del sitio (véase un análisis de este proceso en Girón López, La alcaidía perpetua del Generalife y su pleito: "el pleito del Generalife", pp. 37-47). Para comprender cómo un edificio que pertenecía al real patrimonio desde la ocupación de la ciudad por los Reyes Católicos acabó vinculado a una familia nobiliaria radicada en Italia, véase García Luján, El Generalife. Jardín del Paraíso, pp. 21-33.

19 Véase al respecto Viñes Millet, "Documentos sobre el Generalife. Su estado a mitad del siglo XVIII según el reconocimiento general de sitios reales", pp. 106-108. Con agudeza diría Richard Ford: «Esta residencia [...] pertenece ahora al Marqués de Campotejar, de la familia de los Grimaldi Gentili. Se encuentra ausente y reside en Génova; de modo que el verdadero dueño, como de costumbre, es el administrador»; Ford, Granada. Escritos con dibujos inéditos, p. 81. En el siglo XVIII tanto el edificio como sus jardines atravesaron largos procesos de deterioro y obligaron a intervenir a la Chancillería y a los maestros de obras de la Alhambra para evitar su ruina. El viajero francés Jean François Peyron visitó el Generalife en 1778 y lamentó que perteneciera a "propietarios insensibles», pues encontró sus aterrazamientos reducidos «a simples cañaverales, como los de un claustro de capuchinos»; Peyron, Nouveau voyage en Espagne, p. 209.

${ }^{20} \mathrm{El}$ granadino es calificado en el informe dirigido al rey como «une de ses créatures, nominé Argote», ANF, 381 AP/30, dossier 14. Puede comprobarse que Argote no fue incluido en la administración de Jaén en López Pérez y Lara Martín-Portugués, Entre la guerra y la paz. Jaén (1808-1814), pp. 333-349.

21 Su presencia en Segovia la desvela López Tabar, Los famosos traidores. Los afrancesados durante la crisis del Antiguo Régimen (1808-1833), pp. 61-62. 
breve, estaba escrito en 1807, pues Argote alude en él a «los terremotos del año pasado», que son los que sacudieron la ciudad en octubre de 1806. Según Richard Ford el libro apareció en el verano de 1812 con una breve tirada, pero ésta se perdió casi en su totalidad cuando en septiembre se retiraron las tropas francesas de Granada y, temeroso de sus compatriotas, Simón de Argote se marchó con ellas.

Richard Ford conoció a Argote dos décadas después y tuvo con él una larga conversación sobre las «hazañas de Sebastiani». Un desencantado Argote le reconoció tácitamente que Sebastiani se había enriquecido con el expolio de la ciudad y le confesó que nunca había visto la edición del tercer tomo de sus Nuevos paseos, porque estaba en imprenta cuando tuvo que evacuar la ciudad y los pocos ejemplares editados se perdieron. Todo parece indicar que en el último tramo de su vida Argote era una persona acabada intelectualmente y probablemente arruinada por los avatares de la derrota josefina ${ }^{22}$. La voladura por las tropas napoleónicas de una parte de las murallas de la Alhambra debió de suponer para este enamorado de las antigüedades árabes un duro golpe. Al menos un ejemplar de ese tercer volumen se salvó, y fue reeditado en facsímil en 1985 con una breve introducción de Antonio Domínguez Ortiz.

No sabemos si Argote tenía preparados el resto de los volúmenes que completarían su visión de Granada. Mucho se ha especulado sobre esto y no son pocos los que han buscado el manuscrito. Ahora podemos afirmar que por lo menos había redactado un nuevo capítulo dedicado al Generalife y sus contornos. Cabe preguntarse por qué no integró este capítulo en el tercer volumen de su obra, donde habría encajado perfectamente. ¿Deseaba revisarlo tras las obras de fortificación emprendidas por los franceses nada más llegar a la ciudad y que tanto desvirtuaron el entorno del palacio nazarí? ¿Formaba parte de un nuevo tomo listo para la publicación en el cual estaban comprendidos otros edificios de Granada?

Los trece folios del manuscrito del Generalife están numerados del 71/1 a 71/13; cabe suponer que el primer número indica el cuadernillo y el segundo la página. Sorprende, sin embargo, que las hojas estén de-

22 Suponemos que fue en Granada donde Richard Ford habló con Argote, pero tampoco queda claro pues lo único que dice es: «Empleó a Argote como su chacal, y de boca de éste conocemos los detalles de sus hazañas»; Ford, Granada, pp. 22 y 87. 
sordenadas, aunque la numeración al pie las muestre como consecutivas, lo cual hace pensar que fueron numeradas de una manera descuidada o precipitada. Al igual que en los tres tomos dados a la imprenta, el autor se dirige al público, lo que prueba que el texto estaba preparado para su publicación y que Argote no entregó a José Bonaparte una versión adaptada de su manuscrito. También hay referencias a su descripción de la Casa Real, que remiten al lector a los tomos precedentes, referencias que habrían sido prescindibles si hubiera redactado el texto expresamente para el monarca.

José Bonaparte perdió su archivo en la batalla de Vitoria y se apropió de él el duque de Wellington. Este archivo estuvo en Gran Bretaña hasta que el Estado francés lo adquirió en 1977 y pasó a formar parte de los Archives Nationales de France, pudiéndose consultar en la sede que éstos tienen en París $^{23}$.

\section{Aproximación crítica a la obra de Simón de Argote}

Simón de Argote apostó en los Nuevos paseos por una exposición ordenada frente a los caóticos diálogos del clérigo Juan Velázquez de Echeverría, autor cuyo estilo anticuado lo convierte, a decir de María Soledad Carrasco Urgoiti, en un «epígono del Siglo de Oro», mientras que en Simón de Argote vemos a una persona de sólida formación ilustrada y «representante genuino de la mentalidad prerromántica»; y añade esta autora que en la obra «racionalidad y enciclopedismo conviven con una sensibilidad abierta al culto de la naturaleza y proclive a la evocación $»^{24}$. Argote da pruebas de un carácter ingenioso, un gusto artístico cultivado y una notable precisión, y reconoce que tiene como modelo los libros análogos que se publican en «la Francia que es uno de los Reynos de la Europa que procura con mas actividad en el dia poner en movimiento todos los resortes que obran las mejoras de los Pueblos ${ }^{25}$. Como ha señalado Juan Calatrava, en estos paseos Argote

${ }^{23}$ El archivo de José Bonaparte consta de 37 cajas, aunque hay una sección del propio Wellington y su lucha con Napoleón. El manuscrito del Generalife se encuentra bajo la signatura: $381 \mathrm{AP} / 15$, Dossier 6.

${ }^{24}$ Carrasco Urgoiti, “«Paseos» (Juan Velázquez de Echeverría) y «Nuevos paseos por Granada» (Simón de Argote): Haz y envés de un libro guía”, pp. 176-178.

${ }_{25}$ Sus objetivos y método los expone Argote en la introducción (Argote, Nuevos paseos históricos, artísticos, económico-políticos, por Granada y sus contornos, pp. 3-16). 
mostró su escepticismo hacia la religiosidad devocional criticando los mitos fundacionales del catolicismo granadino, en particular los fraudes del Sacromonte, y dio a su descripción de la ciudad un carácter científico y desacralizado en el que se mostraba deudor de las concepciones urbanas y arquitectónicas de la Ilustración ${ }^{26}$. Sin embargo, no era arabista y, pese a los méritos de su exposición, cuando trata de las inscripciones de los palacios nazaríes depende de las traducciones de Velázquez de Echeverría. Además comete algunos errores en la cronología musulmana cuando hace un resumen histórico de la historia del Islam en la Península Ibérica, aspecto sobre el cual un amigo le llamará la atención en un pequeño folleto publicado en $1807^{27}$.

Las fuentes bibliográficas que utiliza para elaborar su obra, y que encontramos también citadas en el capítulo del Generalife, son clásicos de la historiografía granadina como Luis de Mármol y Carvajal (Historia del rebelión y castigo de los moriscos del reino de Granada, 1574), Diego Hurtado de Mendoza (Guerra de Granada, 1574), Francisco Bermúdez de Pedraza (Historia eclesiástica de Granada, 1638) y, sobre todo, el citado libro de Velázquez de Echeverría. Este autor, a quien Argote pudo conocer personalmente, encarna esa Granada oscurantista que tanto detestaban las personas de espíritu ilustrado y admiradoras de Francia. El clérigo menor Juan Velázquez de Echeverría (1729-1808) fue colaborador de Cristóbal Medina Conde (1726-1798), condenado como uno de los autores de los falsos hallazgos del Albaicín, persona que fue la que en realidad empezó a redactar los Paseos por Granada y sus contornos. En la Alcazaba Cadima, sita en el Albaicín, junto a auténticas ruinas romanas se enterraron piezas falsas que buscaban probar la veracidad de los hallazgos del Sacromonte ${ }^{28}$.

26 Calatrava, "Un retrato de Granada a principios del siglo XIX: los «Nuevos Paseos» de Simón de Argote", pp. 95-110.

27 Agradezco al historiador José Tito Rojo que me llamara la atención sobre este folleto. Lo que plantea FARN son correcciones cronológicas en la traslación de años musulmanes al calendario cristiano; FARN, Cartas escritas por F. A. R. N. a un amigo suyo, en las que hace reflexiones y reparos sobre varias cosas de los Nuevos Paseos históricos, artísticos, económico-políticos por Granada y sus contornos. Las que pueden servir de suplemento a dichos Paseos; y al mismo tiempo dar luz para hacerse cargo de su mérito, p. 6.

${ }_{28}$ Los hallazgos del Albaicín fueron objeto de un estudio ya clásico de Manuel Sotomayor (Cultura y picaresca en la Granada de la Ilustración. D. Juan de Flores y Oddouz). Un relato de los hallazgos y perfiles actualizados de los protagonistas de estos acontecimientos puede verse en Barrios Aguilera, La invención de los libros plúmbeos. Fraude, historia y mito, pp. 391-403. 
No es de extrañar que en los Paseos a todo se le intente buscar un origen romano, incluido el Generalife. Velázquez de Echeverría ofrece una descripción dialogada del Generalife distribuida y mezclada con otros temas en varios de sus paseos, lo que da una visión bastante confusa de la almunia y sus contornos. Simón de Argote polemiza a lo largo de sus Nuevos paseos con Velázquez de Echeverría, particularmente cuando éste se desliza hacia lo inverosímil. En el capítulo del Generalife opta por ignorar las consideraciones del sacerdote sobre el origen romano de la acequia del Rey ${ }^{29}$, aunque toma todas las traducciones que ofrece de las inscripciones de la almunia y las presenta de una manera más ordenada. Precisamente es el orden una de las virtudes de la exposición de Simón de Argote, el cual nos ofrece un itinerario por el palacio, sus jardines, su colección de retratos y las ruinas árabes de sus contornos, que constituye un excepcional documento sobre el estado del lugar antes de que los franceses alteraran esa zona con sus obras de fortificación.

Cabría pensar que la obra mucho más moderna de Simón de Argote se impondría claramente sobre la de Velázquez de Echeverría como referencia sobre la Alhambra en la historiografía granadina. Sin embargo esto no ocurrió con claridad; no sólo el autor cayó en desgracia por afrancesado y el tercer tomo se convirtió en una rareza, sino que además en 1814 se publicó una reedición de los Paseos con notas a pie de página que actualizaban su contenido, notas a cargo de Julián María Pérez, un fernandino que daba por buenas las supercherías del Sacromonte y que ignoraba por completo la obra de Simón de Argote. Estos factores hicieron que durante el largo periodo de la restauración absolutista fuera más accesible el enrevesado y barroco texto de Velázquez de Echeverría.

En cuanto a la descripción del Generalife que hace Simón de Argote, de haberse publicado habría destacado como la más precisa hasta ese momento, pero quedó por completo inédita. En fin, no habría aproximaciones a la antigua almunia nazarí de cierta modernidad formal hasta la aparición de las guías de Miguel Lafuente Alcántara (1843) y José Giménez Serrano (1846).

${ }^{29}$ La Acequia Real la considera probable obra romana porque en la Alcazaba Cadima (Albaicín) se encontró una inscripción mencionando la traída de aguas al Capitolio de Iliberri, argumento desde luego muy endeble. Menciona el Generalife en el paseo IX, le dedica por completo el paseo X y parte de los paseos XL y XLI; Velázquez de Echeverría, Paseos por Granada y sus contornos, p. 37. 
Hechas estas consideraciones paso a transcribir el texto de Simón de Argote al que añado notas analíticas para orientar y comentar su lectura. Entre paréntesis y con letras se remite a las tres notas autógrafas del autor, ubicadas a pie de página en el original y que aquí he situado al final. Por otra parte, ilustro el artículo con dos imágenes poco conocidas del Generalife descubiertas recientemente en el British Museum entre los cuadernos de Grecia del arqueólogo inglés Sir William Gell. En lápiz y tinta los dibujos reflejan la almunia nazarí en la época en la cual Simón de Argote redactó su texto ${ }^{30}$.

\section{Apéndice: \\ «Palacio de Generalif (Palais du Generalife à Grenada, S. A.)»}

Este Palacio se llama así por haber sido destinado a casa de recreo de los Reyes Moros, en la que para descanso de los graves y serios negocios del gobierno, se entregaban al placer de la musica, y de la Zambra o bayles; pues aquella voz arabiga, según Luis del Mármol, significa Huerta del Zambrero o Tañedor. Tambien pudo derivarse este nombre de la circunstancia de haver sido mandado edificar por un Príncipe Moro, llamado Omar, tan aficionado a la musica, que se retiro a vivir aquí para darse de todo punto al ejercicio de ella, como dice Bermudez de Pedraza. Sea, lo que se quiera de esta etimologia, es cierto que este edificio por el lugar eminente en que está situado, goza de los ayres mas frescos y mas puros; ofrece el quadro natural de las vistas mas agradables; y por la abundancia de aguas que lo riegan, presenta un teatro de verdura y de saludable vegetación, que lo inunda de ambrosia, haciendolo la mas digna mansión de la alegria pura, y de los placeres sin remordimiento ${ }^{31}$.

30 Agradezco al arquitecto Carlos Sánchez Gómez la noticia sobre la existencia de estas imágenes. Aunque el British Museum las fecha en 1811, diversos detalles delatan que son previas a la guerra. Gell realizó una escala en el puerto de Málaga en alguno de los viajes que hizo a Grecia entre 1801 y 1806.

31 Argote sigue a Velázquez de Echeverría — salvo la digresión de éste sobre un precedente romano del edificio-, quien afirma que el nombre correcto es Generaliph, pero la gente lo llama Generaliphe, y vendría de Huerta del Zambreo, Tañedor o Primer Músico, porque el príncipe Omar sería muy aficionado a la música (Velázquez de Echeverría, $P a$ seos por Granada, pp. 38 y 256). Una recopilación de todas las explicaciones sobre el nombre y origen del edificio puede verse en Valladar y Serrano, Guia de Granada. Histo- 
Esta distante un tiro de bala del R. ${ }^{1}$ Alcazar de la Alhambra, y tiene dos puertas que le dan entrada, una que mira al Poniente, y otra al Medio dia.

Esta ultima que es la principal, es accesible por una anchurosa senda o paseo formado de cipreses y otros arboles y arbustos ${ }^{32}$.

La fachada de esta parte del edificio está renovada enteramente, y solo conserva un agimes del tiempo de los Arabes. El portico o vestíbulo se forma por tres piezas; la de en medio de cinco y media varas de largo y una y quarta de ancho ${ }^{33}$, y en uno y otro lado hay arcos de erradura, adornados de boceles, concavos, y archivolta afestonada con enjutas de ojas y flores, para entrar a las dos laterales ${ }^{34}$.

El jardin a que da entrada por tres arcos sostenidos de columnas de marmol blanco, tiene setenta varas de largo y quince de ancho. Por en medio de este corre una acequia de vara y media de ancho, y de igual profundidad, guarnecida de cipreses, mirtos y arrayanes que forman arcos en toda su extensión. A los lados de acequia habia un canal continuado en toda su longitud, formado de piezas quadrilongas de loza vidriada, que en el dia están rellenas de material ${ }^{35}$.

En el muro o pared que está a la derecha del Jardin hay una puerta de entrada a un quarto interior, muy digna de notarse por estar adorna-

ria, descripciones, artes, costumbres, investigaciones arqueológicas, pp. 425-428. Hoy se piensa que el nombre es la corrupción de Ŷannat al- ${ }^{-A r i ̄ f ~ q u e ~ s e ~ t r a d u c e ~ c o m o ~ « j a r d i ́ n ~ d e l ~}$ arquitecto» y que el edificio fue construido por el sultán Muhammad II a finales del siglo XIII, siendo objeto de tres reformas durante la etapa nazarí (Bermúdez López, La Alhambra y el Generalife. Guía oficial, p. 219).

${ }^{32}$ En época musulmana la puerta principal era en realidad la de poniente, pues permitía al monarca acceder rápidamente desde la torre de los Picos de la Alhambra, aunque a principios del siglo XIX debía de usarse poco. No obstante, Lafuente Alcántara sí se percatará de que es el acceso principal y lo describirá con detalle (Lafuente Alcántara, El libro del viajero en Granada, pp. 199-200). El abandono de este acceso continuó hasta que fue desescombrado en 1924 por el arquitecto Felipe Jiménez Lacal y restaurado por Torres Balbás en 1934-1935 (Vílchez Vílchez, El Generalife, pp. 26 y 40).

33 Argote comete un desliz: la medida correcta debería ser «cinco y media varas de largo y tres y quarta de ancho».

${ }_{34}$ El lado sur del palacio era en efecto el más transformado en época cristiana, pero también lo había sido en época musulmana cuando se le añadió un segundo cuerpo (Vílchez Vílchez, El Generalife, p. 55).

${ }^{35}$ El estado del jardín, denominado en el siglo XVI de los Arrayanes y hoy de la Acequia, que conoció Simón de Argote y que puede ilustrarse con el grabado y el plano contemporáneos de Alexandre Laborde, difiere sustancialmente del que hoy podemos ver, producto de las sucesivas restauraciones que desde 1959 rebajaron el suelo buscando el nivel medieval, rehicieron los andenes, renovaron la vegetación, etc. (Vílchez Vílchez, El 
dos sus tableros de bajos relieves del mejor gusto, que forman subientes con quatro figuras desnudas en cada uno, en actitudes diversas aunque todas muí pintorescas; enredadas entre pabellones, bichas, mascarones y otros caprichos; y en el marco con cabezas de viejo, aladas, y macollas entrelasas que las terminan ${ }^{36}$.

Del otro lado del jardin hay una galeria de vara y media de ancho con diez y seis arcos, los de la parte exterior renovados, y los interiores sostenidos por machones, sin conservar mas adorno que su archivolta afestonada ${ }^{37}$.

En medio de esta galeria es de creer que huvo algun mirab, según el ornato de que se conserva una parte en los tableros de estuco de su fachada, que terminan en columnitas arabes sosteniendo mensulas que recibirian la cubierta. En el día hay una capilla en su lugar ${ }^{38}$.

Generalife, pp. 113-114). El dato del canal de azulejos que flanqueba la acequia no to he visto citado por ningún autor. Por otra parte Argote no habla de los saltadores de agua, que tampoco se ven en los grabados románticos, lo que confirma que debieron de ser añadidos a mediados del siglo XIX, que es cuando empiezan a aparecer en las fotos. Un minucioso análisis de la evolución de este jardín en Tito Rojo y Casares Porcel, El jardín hispanomusulmán: Los jardines de al-Andalus y su herencia, pp. 230-250 y 268-296.

${ }^{36}$ Lafuente Alcántara dice que por esta puerta se accede a las habitaciones donde vive el administrador y describe sus hojas así: «Tienen graciosos relieves de madera, representando sátiros, faunos y figuras caprichosas. Esta labor revela desde luego, que es debida a un artista exento de las prohibiciones del Corán»; Lafuente Alcántara, El libro del viajero, p. 202. Giménez Serrano (Manual del artista y del viagero en Granada, p. 152) va más lejos y atribuye las «admirables» tallas a Alonso Berruguete. Medio siglo después Gómez Moreno señala que la puerta «fue deshecha hace algún tiempo y sus mejores tableros llevados a Italia»; Gómez-Moreno González, Guía de Granada, 1892, p. 168. Por otra parte, numerosos autores consideraron que este costado del patio era de fábrica enteramente cristiana, aunque tras el incendio del 8 de diciembre de 1958 Jesús Bermúdez Pareja estudió las estructuras llegando a la conclusión de que en realidad la crujía se componía de dos viviendas musulmanas con dos cuerpos de alzada, las cuales tuvieron decoraciones de zócalos de azulejos y yeserías; localizó también una escalera que interpretó como el acceso a un baño que estaría bajo el jardín del Ciprés de la Sultana o el jardín del Pino (Bermúdez Pareja, "El Generalife después del incendio de 1958", pp. 9-40, 25 y 33-37).

${ }_{37}$ Aunque numerosos autores han considerado la galería obra posterior a la conquista tanto a partir del prejuicio de que los jardines musulmanes deben ser cerrados como por la presencia de pinturas con el lema de los Reyes Católicos, los últimos estudios se inclinan por la hipótesis de que el jardín nazarí se abría al paisaje (véase Orihuela Uzal, Casas y palacios nazaries, siglos XIII-XV, p. 212 y Tito Rojo y Casares Porcel, El jardín hispanomusulmán, pp. 277-280).

${ }^{38}$ La capilla tenía un lienzo de la Inmaculada Concepción (García Luján, El Generalife, p. 54). En 1922-1923 los arquitectos Eladio Laredo y Felipe Jiménez Lacal descubrieron dos capas superpuestas de ornamentación musulmana; diez años después Torres Balbás restituyó el aspecto nazarí del lugar, que no era un oratorio sino un mirador (Vílchez Vílchez, El Generalife, pp. 68-69). 
El testero del jardin se forma por galeria de quatro arcos iguales, y uno mayor en el medio, sostenidos por seis colunas de mármol Macael. El adorno interior de estos arcos es de boceles concavos, y en sus caras de calados afiligranados; las archivoltas son afestonadas, y estan inscriptos en recuadros guarnecidos de faxas con motes en letras africanas entrelazadas con nervios, ojas y flores, en que se refiere solo Dios es vencedor: La omnipotencia a Dios.

En la parte interior de la galeria se ven en los extremos dos grandes nichos o capillitas de vara y media de ancho, y dos de fondo con doble arco de erradura, y adornos semejantes a los que describimos de la casa Real de la Alhambra, el de la izquierda sirve en el dia de entrada a piezas interiores. Al mismo genero pertenecen los revestimientos de estuco que cubren las paredes interiores de la galería; es decir que son faxas de letreros, cenefas con figuras romboidales y estrelladas, todo terminado con motes. El techo es labrado con labores exquisitas, y tiene repartidos graciosos cupulinos.

En medio de esta galería está la puerta de entrada al salon principal, formada por tres arcos, que estrivan en dos colunas de marmol, y dos machones a los lados. Estos se cierran con una puerta de dos ojas de dos varas y media de ancho, y cinco de alto cada una; cuyos exes giran sobre gorrones salientes de madera, que tienen la forma de capiteles de coluna.

El salon tiene quince varas de largo, quatro de ancho y seis de alto hasta la cornisa: en sus extremos hay alcobas o alhatises ${ }^{39}$ formados por arco circular, sostenido de colunas. Su ornato, aunque con algunas variedades, y menos profusion, es igual al de la antesala de Comaresch, circundado de motes y letreros, que en la mayor parte no pueden leerse. El artesonado que cubre esta sala es de lo mas exquisito que trabajaron los Moros por el gusto de sus embutidos de maderas pintadas.

A este sigue un mirador quadrado de quatro y media varas de lados, formado de quatro arcos, aunque falta el del agimez o ventana, que está renovado enteramente. Por evitar el fastidio de las repeticiones, no entramos en la descripción prolixa de su adorno de estuco, que es de lo mas trabajado y exquisito del genero arabesco ${ }^{40}$.

\footnotetext{
39 No es un error de transcripción, Argote habrá querido decir alhanías, pero ha escrito «alhatises».

${ }^{40}$ Una descripción muy precisa de los ornamentos del pabellón norte puede encontrarse en Pavón Maldonado, "El Generalife", pp. 12-16.
} 
A los lados de este mirador hay dos piezas enteramente renovadas, o hechas a la moderna. Una de ellas está destinada a conservar la memoria de los sucesores en el Señorio y Alcaidia de esta Casa que los Reyes Catolicos conquistadores de este Reyno, dieron a Gil Vazquez Rengifo de Avila en premio de los servicios de su Padre Juan Vazquez el qual según refiere Ayora, murio peleando en la Vega de Granada. Después por casamiento de D. ${ }^{\mathrm{n}}$ Pedro de Granada Venegas con D. ${ }^{\mathrm{a}}$ Maria Rengifo, hija unica de aquel pasó esta Alcaydía y Señorío a la Casa de Granada, sucediendo en ella por los servicios de su Padre D. ${ }^{\mathrm{n}}$ Alonso de Granada Venegas, cuya merced se continuó por el Rey Felipe $2^{\circ}$ a D. ${ }^{n}$ Pedro de Granada marques de Campo Rey, y vizconde de Miravelles, hasta que Felipe $4^{\circ}$ la perpetuó en su Casa y Mayorazgo, concediendole la jurisdicción del cerro del sol y antiguos edificios Moriscos, que se hallasen en el termino de Generalif, con mezo mixto imperio horca y cuchillo.

Para prevenir las equivocaciones y errores a que dan lugar las voluntarias relaciones que se hacen de los personages que representan los retratos que hay en esta sala, daremos la lista de ellos, según el orden en que están colocados ${ }^{41}$.

En el testero hay un gran quadro del arbol de la genealogía y descendencia de los Reyes de Zaragoza y Granada de quien desciende D. ${ }^{n}$ Pedro de Granada Venegas, Señor de Campotexar y Jayena. A los lados de este están otros dos, uno de dos tercias de alto y media vara de ancho que es retrato en medio cuerpo de Mûlahavven, Ynfante de Granada, con corona radiada; y otro de vara y quarta de alto, y una de ancho, en el que en la misma forma está representado con bonete y corona perlada Aben hud, y lleva este rotulo: Aben-hud Rey de Granada y Cordoba y de lo mas de Andalucia, del linaje de los Reyes de Zaragoza, de Aragon y de los godos: fue eminente Rey en Justicia, verdad y liberalidad. A un lado tiene pintado el escudo de armas que

${ }^{41}$ La primera descripción de los retratos y del árbol genealógico la había realizado antes Velázquez de Echeverría, Paseos por Granada, p. 39. Giménez-Serrano denunciaría que los letreros de los retratos «están maliciosamente trocados»; Giménez-Serrano, Manual del artista, p. 159. La más precisa y ordenada descripción de los cuadros en Valladar y Serrano, Guía de Granada, pp. 435-441. Los retratos de soberanos españoles se conservan en la Casa de los Tiros desde 1921, mientras que los de los alcaides del Generalife fueron trasladados a Italia (García Luján, El Generalife, pp. 44-45). Las salas de los retratos que flanqueaban el mirador norte fueron desmanteladas por Torres Balbás entre 1927 y 1932 (Vílchez Vílchez, El Generalife, p. 128). 
lleva en campo blanco, una faxa negra y en ella el mote en letras africanas: solo dios es vencedor.

Al lado del Jardin sigue el primero de dos varas y media de alto, y vara y media de ancho, de cuerpo entero, armado con peto y espaldar, con cetro en la mano, y al pecho la cruz del orden militar de $\mathrm{S}^{\mathrm{n}}$.tiago, pisando sobre vanderas y estandartes morunos, y de un lado una cabeza de moro cortada. En el campo del quadro hay tambien pintada una palma con este letrero: La condicion de la palma en el cuerpo y en el alma. Se ha creido ser este retrato de Garcilaso de la Vega, pero su escudo de armas, que no se lee el mote ave maria, y que indubitadamente es de la Casa de Granada, indica ser de D. ${ }^{\mathrm{n}}$ Pedro de Granada primer Conde de Campotexar, que se hizo cristiano y sirvio a los Reyes Catolicos. El segundo que representa un personage armado del mismo modo, cetro y espada, que se dice ser de Ponce de Leon, por tener a los pies una figura de este animal, es de D. ${ }^{\mathrm{n}}$ Alonso de Granada Venegas, $2^{\circ}$ sr. y Alcayde. El tercero es de D. ${ }^{a}$ Juana de Mendoza, su muger. Sigue el de D. ${ }^{n}$ Pedro segundo de Granada, tercer Sr. y Alcayde, vestido de Corte y un perro a los pies, sobre el que dice $=$ año de 1562. Después está el de D. ${ }^{\mathrm{n}}$ Alonso de Granada Venegas, quarto Sr. y Alcayde de esta casa, que se atribuye a D. ${ }^{\mathrm{n}}$ Fernando del Pulgar. En testero de enfrente está el Infante de Granada hijo del Rey Josef Señor de Almería. El de $\mathrm{D}^{\mathrm{a}}$. Catalina de Granada, hija de D. ${ }^{\mathrm{n}}$ Pedro tercero de Granada, la que casó con D. ${ }^{\mathrm{n}}$ Estevan Lomlin, y el del $\mathrm{D}^{\mathrm{n}}$. Pedro tercero de Granada, quinto Señor y Alcayde.

Hay otras salas altas en que se ven tambien retratos; y entre ellos están repetidos los de $\mathrm{D}^{\mathrm{n}}$. Pedro $1^{\mathrm{o}}$, D. ${ }^{\mathrm{n}}$ Pedro $3^{\mathrm{o}}$ y D. ${ }^{\mathrm{n}}$ Alonso de Granada Venegas, $4^{\circ}$ de esta Casa. Además está de medio cuerpo el de $\mathrm{D}^{\mathrm{n}}$. Juan de Granada ultimo poseedor y Alcayde; y el de María de Granada Monja de S. ${ }^{\text {ta }}$ Isabel.

Al lado del N. sobre el jardín de la entrada hay otro [patio] de veinte y siete y media varas de largo y diez y ocho y media de ancho, que llaman del estanque y tiene en medio una alberca pequeña de cinco y media varas en quadro y una profundidad ${ }^{42}$.

42 Este patio se conoció en el siglo XVI como patio de los Cipreses y hoy se le llama del Ciprés de la Sultana, pues desde mediados del siglo XIX las guías sólo hacen referencia al más grande de los cipreses, el cual murió hacia 1970. El jardín es del renacimiento y se ha discutido si fue realizado sobre un antiguo jardín musulmán o sobre las ruinas de un presunto baño; en cualquier caso la existencia de una alberca está documentada desde mediados 
En el centro de ella se levanta sobre pedestal una taza de mármol blanco de una vara de diámetro, con saltador, y quatro mascarones en sus bordes. Está en medio de un rectangulo de seis varas de ancho y quince de largo que forma un quadro de jardin circundado de un estanque de tres varas de ancho, y otra tanta profundidad enrededor del qual hay saltadores inclinados de manera que quando echan agua forman juegos en forma de arcos.

Al pie de este estanque corre la acequia que conduce el agua a la R. ${ }^{1}$ Fortaleza de la Alhambra, y de uno otro lado del jardin hay un paseo que da vuelta, y tiene tres varas de ancho. Se adorna con algunos cipreses, entre los que se ven quatro mui corpulentos, de los que el mayor tiene vara y media de diámetro. Es vulgar tradición que al pie de estos cipreses, es donde dixo el Zegrí acusador de la Sultana, que la habia visto entretenida en adulteros amores con Albin Ahmad, el mas poderoso y rico de los Aben-cerraxes; y por esto se conocen hasta el dia con el nombre de los cipreses de la Reyna sultana. Pero esta especie no merece otro credito que la de el pretendido adulterio y acusacion, pues una y otra no tienen mas fundamento que el Romance de las Guerras Civiles de Granada ${ }^{43}$.

Al frente de este jardín se ve una escalera de cantería de tres varas de ancho, por la que se sube a una bobeda circular formada de laureles, que da salida a varias galerías, huertecillos, y otros sitios amenos. Uno de ellos forma plazeta cubierta de parrales con saltador en medio, y a su derecha hay otras escaleras que conducen a un postigo de esta casa, ofreciendo varios descansos, y la extraña y alegre variedad de sus pasamanos que se forman de canales de vidriado por donde corren con

del siglo XVI y el jardín desde los años posteriores a la Guerra de las Alpujarras (Tito Rojo y Casares Porcel, El jardín hispanomusulmán, pp. 393-394). En los muros del patio había pinturas con «escenas de costumbres árabes y cristianas»; Lafuente Alcántara, El libro del viajero, p. 209. Teophile Gautier también cita estas pinturas cuando dice que los «muros conservan huellas de frescos del siglo XVI representando motivos de arquitectura rústica y paisajes»; citado por García Luján, El Generalife, p. 71. Estas pinturas al fresco fueron enlucidas y quedaron en parte al descubierto a raíz de modernas restauraciones, aunque están muy deterioradas; el hallazgo de unas monedas fechadas en 1604 ha llevado a especular con la posibilidad de que las pinturas sean de esa fecha (Bermúdez López, La Alhambra y el Generalife, p. 234). Otros fragmentos de pinturas, fechados en el siglo XVI, se encontraron durante las restauraciones de la nave sur del patio de la Acequia llevadas a cabo por Torres Balbás, pero no se conservaron (Vílchez Vílchez, El Generalife, p. 115).

${ }_{43}$ Argote desprecia de esta manera una leyenda difundida y enriquecida por Velázquez de Echeverría, Paseos por Granada, p. 257. 
rapidez y murmullo las cristalinas aguas que refrescan estos encantados lugares ${ }^{44}$.

A los lados del Sur y del Poniente de la Casa, hay tambien jardines con toda clase de flores, y arboles de exquisitos frutos. La situacion del terreno, que es inclinado en la mayor parte, hace necesario el cultivo de las plantas en bancales y paratas, que presentan la risueña decoracion de escalas anfiteatrales de verdura matizada de los mas bellos coloridos, en medio de la que se respira el mas delicioso perfume; y se multiplica el goze de la existencia al lado de una inmarcesible vegetación.

El Padre $\mathrm{D}^{\mathrm{n}}$. Juan Echeverria en sus Paseos por Granada, dio leídas varias inscripciones de esta casa, que no queremos defraudar al publico, sin embargo de que no nos ha sido posible comprobarlas ${ }^{45}$.

\section{En la cenefa de la galería}

Mi ayuda sea Dios contra el diablo tentador. En el nombre de Dios, que es misericordioso y tiene misericordia. Sea Dios con nuestro Señor el Profeta Mahomet, salvación y salud. Te hemos descubierto triunfo de claridad para que Dios te perdone todo lo pasado, y por venir de todos tus pecados y para que cumpla en ti su mandamiento, y te encamine por camino derecho, y te sublime Dios, que es alta sublimación. El me puso en reposo entre los creyentes para que aumenten fe sobre su creencia. De Dios son todos los Exercitos del cielo y de la tierra. El Dios sabio alto y justiciero para dar la gloria a los creyentes; gloria de la que corren aguas perpetuas en ella, y les perdonará a todos sus pecados. Y atormentará a los escandalizadores, y escandalizadoras, y los multiplicadores y multiplicadoras de Dios (a). Los que ponen en Dios fealdad, y sobre ellos derramará fealdad, y les aparejará el Infierno, y en él los perpetuará. De Dios son los Exercitos celestes y de la tierra.

${ }^{44}$ En 1836 el administrador del Generalife Jaime Traverso construyó al final de la escalera el llamado Mirador Romántico (Lafuente Alcántara, El libro del viajero, p. 209). Se ha apuntado que en ese lugar hubo un oratorio musulmán, algo que hasta el momento no han corroborado hallazgos arqueológicos. Como puede verse, Simón de Argote dice que la escalera lleva a un postigo y no menciona restos de ninguna estructura.

${ }^{45}$ Sobre las inscripciones véase la recopilación de traducciones, en buena medida procedentes de Emilio García Gómez, que se hace en Vílchez Vílchez, El Generalife, pp. 8189 y una reciente y gráfica traducción en Puerta Vílchez, Leer la Alhambra. Guía visual del Monumento a través de sus inscripciones, pp. 328-350. 
El alto Dios y justiciero. Te havemos embiado testificador, y denunciador, y visitador, para que creais en Dios, y su mensagero, y lo honreis, y le hagais comedimientos, y le alabeis de dia y de noche. $\mathrm{Y}$ qualquiera que os saludare a vosotros, saluda en Dios, y porque la mano de Dios está sobre la mano de ellos, en dios toca vuestra barba para aficion perpetua (b). Y qualquiera que os perturbase así mismo se perturba. Y qualquiera que añadiere sobre aquello, que Dios le mandó, por ello se dará gran galardón ${ }^{46}$.

\section{En la ventana de la derecha del Salon}

Ismael es el mayor, el grande el aventajado. Dios le ha dado fama, y establecimiento para vivir, y para ensalzar su estado. Si a su grandeza sirvieres, serás honrado como lo son los Reyes que el procreó, y cuya descendencia hoy le imita. El da vida a los sedientos como el signo de Augurio, y con agua perpetua fomenta la union, y mantiene la Secta ${ }^{47}$.

\section{Sobre la ventana izquierda unos versos}

La ventana que está a la entrada de este dichoso Palacio para servicio y regocijo de la nobleza. Su vista agraciada entretiene los ojos y eleva el corazon para dar a Dios gracias. Y la fuente que desde ella se descubre, con su agua y su frescura, se halla mas ensalzada; y solo la hace mejor la presencia de su Rey, y Señor, quando la mira ${ }^{48}$.

\section{Sobre los arcos del Paseo de la entrada}

La alabanza a Dios el alto, el poderoso, el sabio y después del a nuestro gran Profeta el Señor de los Musulmanes, el justo, el embiado

46 Texto de El Corán. Traducción procedente de Velázquez de Echeverría, Paseos por Granada, pp. 257-258.

47 Traducción procedente de Velázquez de Echeverría, Paseos por Granada, p. 260.

48 Traducción procedente de Velázquez de Echeverría, Paseos por Granada, p. 264. 
de Dios: y después del á su succesor el Rey alto, el Emperador de los Moros, el sublime Abulhagleh, defensor de la ley santa, y sus creyentes: y después del á los piadosos y buenos que guardan la ley. Y decid no hay Dios sino Dios, y Mahomet su Legado. La alabanza a Dios ${ }^{49}$.

\section{Otra en los mismos arcos}

El poder la sublimacion, y la grandeza sea dada a Dios; y el ensalzamiento a el grande Emperador nuestro. ¡O Rey ensalzado, vencedor de tus enemigos! Entras en la batalla como el rayo y cabalgando tan veloz como el Alborac, que parecias caminar ligero de un cabo al otro cabo del mundo. Salvete aquel que caminaba en una noche inmensos espacios, y sea tu guia el Angel grande que le guiaba. Y después de haver defendido la Secta, seas recibido en el Parayso con el Profeta Santo $^{50}$.

\section{Sobre los arcos que salen al Patio del Estanque en versos}

Alcazar hermoso, y de gran primor, se representa con mucha majestad, luces despide de grandeza grande, todo lo baña con su resplandor. Cubrenle nubes de claridad y bondad por todas sus partes con magnificencia; digno es de que se le ofrezcan dones de alabanza, como que tiene algo de divino su adorno. Su jardin adornado de flores, cuyo asunto son las plantas, fixadas con gran fantasia, exala suaves olores. Mueve el aire sus ramas, y causan suavidad y armonía, siendo como una musica concertada. El campo espacioso por todos los alrededores se dexa ver ameno, y en una verdura continua. Abulgüalid, el mejor de los Reyes, temeroso de la Ley de Dios, el que a los justos da reposo, el poseedor de las dos progenies. El que a los descendientes de Mahoma protege; el que se muestra en todo ser a sus vasallos; el que hace valer, el que desprecia lo transitorio y pone sus esperanzas en Dios, y en sus leyes, es el objeto de mi estimacion. Salvate Dios, y date buen hado y

49 Traducción procedente de Velázquez de Echeverría, Paseos por Granada, p. 263.

50 Traducción procedente de Velázquez de Echeverría, Paseos por Granada, p. 263. 
confirme en ti sus altos favores, con los que subas al estado mas alto. $¡ O$ ! siempre tengas ventaja, nunca te falten primores, que has ennoblecido a las labores. Este aposento a ti dedicado, está en un grado de perfeccion, de altura y de firmeza, que puede compararse en su duracion a la secta nuestra. Es un milagro, un triunfo del arte. Y por eso Rey soberano, apoyo de la grandeza, ten por bien de aceptar esta obra, que tu aceptación le dará firmeza, y con ella se hará digna de dedicarse a ti con imponderable ventura y brillará en ella la luz, el reposo, el resplandor, el respeto, la honra, y la bondad de su señor, que será la última perfeccion de su nobleza ${ }^{51}$.

\section{Sobre los arcos de los pilares y la parte de adentro}

Mi ayuda en Dios apedreador del Demonio. En el nombre de Dios que es misericordioso, y tiene misericordia. Sed Dios nuestro Señor piadoso con el Profeta, y sus parientes y amigos. Vuestro Dios y un solo Dios, que no hay otro Dios sino el; piadoso de los piadosos: vivo que siempre está despierto, que no le acomete adormecimiento ni sueño. Suyo es todo lo que hay en el cielo y en la tierra ¿Quién es aquel que podrá hacer por nosotros sino con su voluntad? El sabe todo lo que está baxo de los cielos, y lo que está sobre ellos. No se alcanza cosa alguna de su saber, sino aquello que es su voluntad. Nada huye de su inteligencia. Es el alto y grande. Y decide la verdad de Dios y su Profeta ${ }^{52}$.

\section{Alrededores de Generalif}

Mas arriba de este Palacio y Jardines se ven los fundamentos de una antigua torre, que fabricaron los moros en este sitio, siguiendo la costumbre de establecer este genero de fortificacion en las alturas. Esta parte del cerro que llaman vulgarmente Silla del Moro, por los lugares que domina, se nombra tambien de S. ta Yrene o S. ${ }^{\text {ta }}$ Elena; y se cree

51 Traducción procedente de Velázquez de Echeverría, Paseos por Granada, pp. 264-265.

52 Traducción procedente de Velázquez de Echeverría, Paseos por Granada, p. 268. 
que por haberse dedicado en una hermita a la primera santa. No repitamos la deribación de este nombre por un objeto de importante averiguacion; pero sí creemos mas natural y sencilla la de Xantiren con el que los moros llamaron a todo este cerro, según lo confiesa Bermudez Pedraza, nombre que después se corrompio en el de Santiren. Y últimamente en el de Sta. Elena que es el mas comun ${ }^{53}$.

En el mismo sitio edificaron los Reyes moros otro palacio, que llamaban Darlaroca, que quiere decir según Mármol, palacio de la novia, de que se conservaban los cimientos en tiempo de aquel historiador ${ }^{54}$. El mismo vio las reliquias de otro edificio, situado a las espaldas del cerro, nombrado de los Alixares, cuya labor dice era semejante a la de la sala de la torre de Comaresch. Todos estos edificios tenian sus jardines para recreo, y eran habitados en el verano por los Reyes, pues aunque tenian otros en la Alcazaba con jardines y huertas en la Vega, no moraban en ellos, huyendo del ruido y comunicación del pueblo siempre escandaloso y amigo de las nobedades.

En el mismo cerro a la izquierda del camino de Jesús del Valle está el Algibe de la Lluvia, famoso por las fabulas que se han inventado sobre su mucha antigüedad, y la historia de su fabrica. Bermudez Pe-

53 Velázquez de Echeverría dedicó mucha más atención a estas torres, señalando: «La superioridad del Cerro de Sta. Elena, y Silla del Moro, estaba evitada con dos fortificaciones igualmente inexpugnables que tenian; una sobre la misma punta llamada oy Silla del Moro, y otra cerca del Aljibe de la Lluvia. Estas se comunicaban entre si, y con la Alhambra por varias minas, de suerte, que con el auxilio de ellas se podia todo reputar por una Fortaleza misma». En cuanto al nombre del lugar da la inverosímil explicación de que quiere decir cerro de los Griegos (Velázquez de Echeverría, Paseos por Granada, pp. 38 y 379380). En tiempos de Simón de Argote no había ruinas emergentes de la fortaleza y menos aún de la ermita de Santa Elena que por allí hubo y que él ni siquiera menciona (Torres Balbás, "Dār al-'Arūsa y las ruinas de palacios y albercas granadinos situados por encima del Generalife", pp. 188-191). La realización de empalizadas para baterías y su voladura en la retirada de septiembre de 1812 causaron serios daños a las ruinas. Por cierto que durante las obras de fortificación acometidas por los franceses apareció una pequeña escultura labrada en «pedernal» y que representaba a la sibila Albunea en actitud sedente, según José María Hidalgo, que era el propietario de esta figura, cuya altura era de sólo 24 centímetros (Hidalgo Morales, Iliberia o Granada. Memoria histórico-crítica, topográfica, cronológica, política, literaria y eclesiástica de sus antigüedades, desde su fundación hasta nuestros dias, pp. 384-391).

${ }^{54}$ De este palacio, que hoy prefiere denominarse de Dār al-`Arūsa, Simón de Argote no puede ver ni tan siquiera las ruinas, pero medio siglo antes sí alcanzó a encontrarlas Velázquez de Echeverría (Paseos por Granada, p. 40). Las ruinas fueron de nuevo localizadas en 1933 cuando se plantaban pinos y Torres Balbás las excavó y estudió (Torres Balbás, "Dār al-"Arūsa", pp. 191-196). 
draza, a quien sigue el Padre Echevarria, dice que es tradición antiquisima en Granada que este deposito de aguas fue obra del primer Obispo de esta ciudad S. ${ }^{\mathrm{n}}$ Cecilio; que los Moros lo entendieron asi, y decían manaba por la virtud de un santo, que estaba sepultado en el monte de enfrente, es decir, en el Sacromonte. Otros conjeturan, continua el mismo autor, como el nombre que tiene de S. ${ }^{\text {ta }}$ Yrene virgen y martir, natural de esta misma ciudad.

La prodigiosa inagotabilidad que ha querido atribuirsele a este algibe, sin duda es lo que ha dado motivo a buscarle un origen mas ilustre. Cuenta el mismo Pedraza en el año de 1569, montando este cerro una columna de cinco mil hombres, que capitaneaba el Sr. D. ${ }^{\mathrm{n}}$ Juan de Austria contra los moriscos de Guexar, que habian tocado el rebato de la rebelión el dia veinte de Junio; para descansar de la cuesta y moderar el rigor del calor y de la sed, llegaron a este algibe y bebieron por el orden que pasaban, sacando el agua con un capacete; (c) y después de haber bebido todos, se reconocio que no habia menguado el agua; de lo que se recibio información y se dio testimonio.

No nos ha sido posible averiguar de donde sacó este Autor, a quien copia el $\mathrm{P}^{\mathrm{e}}$. Echevarria, semejante noticia, tan inverosímil, como poco conforme con lo que refieren Mármol y Mendoza de aquella expedición, que se verificó de ida y vuelta en un solo dia. Calculando el tiempo que necesitó toda aquella tropa para beber en los terminos que supone Pedraza, no perdiendo un solo momento en la operación de sacar el agua, y bebiendo cada uno solamente medio quartillo, debieron emplear mas tiempo que el empleado en toda aquella expedición.

El Algibe es quadrado de doce varas de lado. Se compone de quatro naves cubiertas con bobeda mui bien trabajada de ladrillo, cada una de ellas de once varas de largo, tres de ancho, y dos y media de alto; $\mathrm{y}$ en el centro forma un quadro de tres varas de lado y dos y media de alto. En lo alto de su bobeda hay abierto un orificio circular de tres quartas de diámetro, para recibir las aguas de llubia, que aumentan las que recoge por infiltración de una gran parte del cerro en que está situado. Hacia el angulo de la derecha de su parte oriental está abierto para el uso. El grueso de sus muros es de una vara, media perteneciente a las naves del algibe, y la otra media a su fortificación o resguardo. La fabrica es absolutamente arabe, y la distancia en que está de la población, lo ha libertado hasta el día de una entera ruina, con 
que lo amenaza la codicia de aprovechar los ladrillos, que ya ha empezado a atacarlo ${ }^{55}$.

En el mismo cerro de Sta. Elena, casi en frente del Sacro Monte, aunque superior del, se encuentra una grande alberca llamada vulgarmente Albercón del Negro ${ }^{56}$, de quarenta y cinco y media varas de largo y doce y media de ancho con todos sus gruesos, y tres varas de profundidad. Está formada de tapiales de dos varas de espesor, defendidas de una cubierta de ladrillos colocados de canto, destruida ya en la mayor parte. Esta alberca debía proveerse por una noria suntuosamente trabajada que está a la parte del norte, de sesenta y una varas de profundidad; y servía para el riego de jardines y huertos que estaban a la parte de abajo; y corresponderían al pretendido palacio, llamado de los Alijares $^{57}$.

En la falda del mismo cerro de S. ${ }^{\text {ta }}$ Elena en frente de la huerta de fuente peña, hay otro grande estanque, conocido con el nombre de albercón de las damas. Tiene veinte y quatro varas de largo, diez y siete de ancho, y dos de profundidad y su muro está defendido de ladrillos puestos a sardinel en toda su extension, es de tres quartas de espesor. Al frente de este estanque se lebanta una obra de dos cuerpos, de veinte y seis varas de alto. El primero que es de once varas forma un descanso de cinco y media varas de ancho, y tiene una escalera cubierta de doce escalones, para llegar a el. El otro cuerpo parece cons-

55 A pesar de los expolios que cita Argote, el aljibe llegó en buen estado al siglo XX (Torres Balbás, "Dār al-'Arūsa", pp. 196-197). Se llenaba con agua de lluvia y, probablemente también, de la procedente de capas freáticas; entre sus posibles usos se ha especulado con el ganadero o el militar (García Pulido, Análisis evolutivo del territorio de la Alhambra (Granada): el Cerro del Sol en la Antigüedad romana y la Edad Media, tomo II, pp. 385-399).

${ }^{56}$ Las medidas de la alberca indican que Argote se confunde en el nombre y que no se trata del Albercón del Negro, sino de la Alberca Rota (véase un minucioso análisis de esta alberca en García Pulido, Análisis evolutivo, tomo II, pp. 337-343). En realidad, Argote no habla en ningún momento del verdadero Albercón del Negro, que tiene 40 por 17 metros y se ubica por encima de las ruinas del palacio de los Alixares.

${ }^{57}$ Los restos del palacio de los Alijares o Alixares - Argote lo escribe de ambas maneras - estaban enterrados en esta época, aunque décadas después un erudito afirmaba que en la zona «hay esparcidos capiteles de columnas, arabescos, alicatados y trozos de mármol de Macael»; Giménez-Serrano, Manual del artista, pp. 165-166; en 1891 sus ruinas afloraron cuando se ampliaba el cementerio del Haza de la Escaramuza (Gómez-Moreno González, Guía de Granada, pp. 175-176 y Torres Balbás, "Dār al-'Arūsa", p. 200). Las muy pobres estructuras que se conservan fueron consolidadas en 2001 (Bermúdez López, La Alhambra y el Generalife, p. 253). En realidad parece que Argote se refiere aquí no a las ruinas del palacio de los Alixares, sino a las del palacio de Dār al- Arūsa (véase García Pulido, Análisis evolutivo, tomo II, pp. 355-367). 
truido para contener el terreno, y tiene quince varas. El agua de que se surte este albercón viene de Generalif, y su salida es a la huerta de fuente peña ${ }^{58}$.

Al fin del cerro llamado de los Alixares se ve tambien otro estanque de veinte y media varas de largo, ocho de ancho, dos de profundidad, y sus muros de media vara de espesor. No sabemos de donde pudo recibir el agua, pero su uso así como el de los que hemos escrito, fue de riego a jardines o fuertecillos de casas de recreo de los Reyes Moros y su familia ${ }^{59}$.

\section{Notas de Simón de Argote}

(a) Alude a los cristianos por la trinidad de las personas que reconocen en Dios.

(b) Los orientales se saludan tocándose la barba y aun besándosela, según antes hemos dicho.

(c) Pieza de la armadura antigua que cubría la cabeza.

58 Este albercón fue reparado en 1926-1927 (Torres Balbás, "Dār al-'Arūsa”, p. 191), fechas en las que Torres Balbás construyó un segundo albercón de similares dimensiones, al que décadas después siguió un tercero realizado por Prieto Moreno (Bermúdez López, La Alhambra y el Generalife, pp. 243-246). Modernas excavaciones han sacado a la luz un sistema de pozos que sirvieron para alimentar el albercón y que quedaron en desuso cuando los propios nazaríes trazaron la acequia del Tercio (Malpica Cuello, "El complejo hidráulico de los Albercones", p. 84).

${ }^{59}$ Las medidas coinciden con las de la alberca del palacio de los Alixares (véase al respecto García Pulido, Análisis evolutivo, p. 275). 


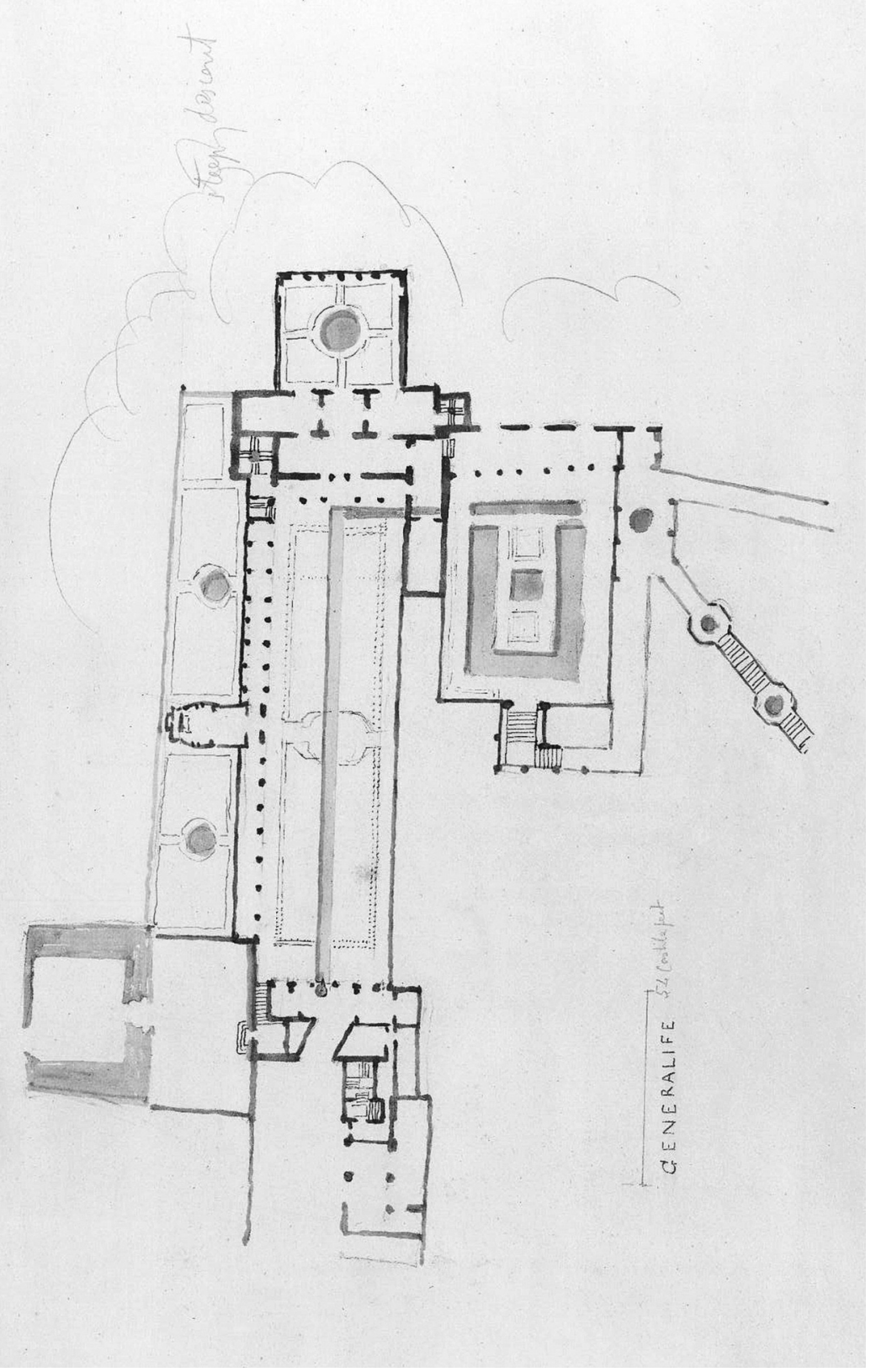

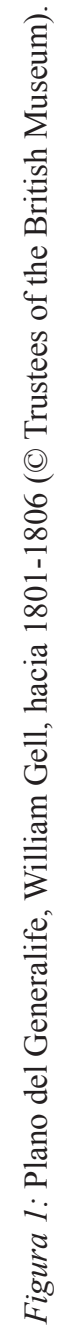




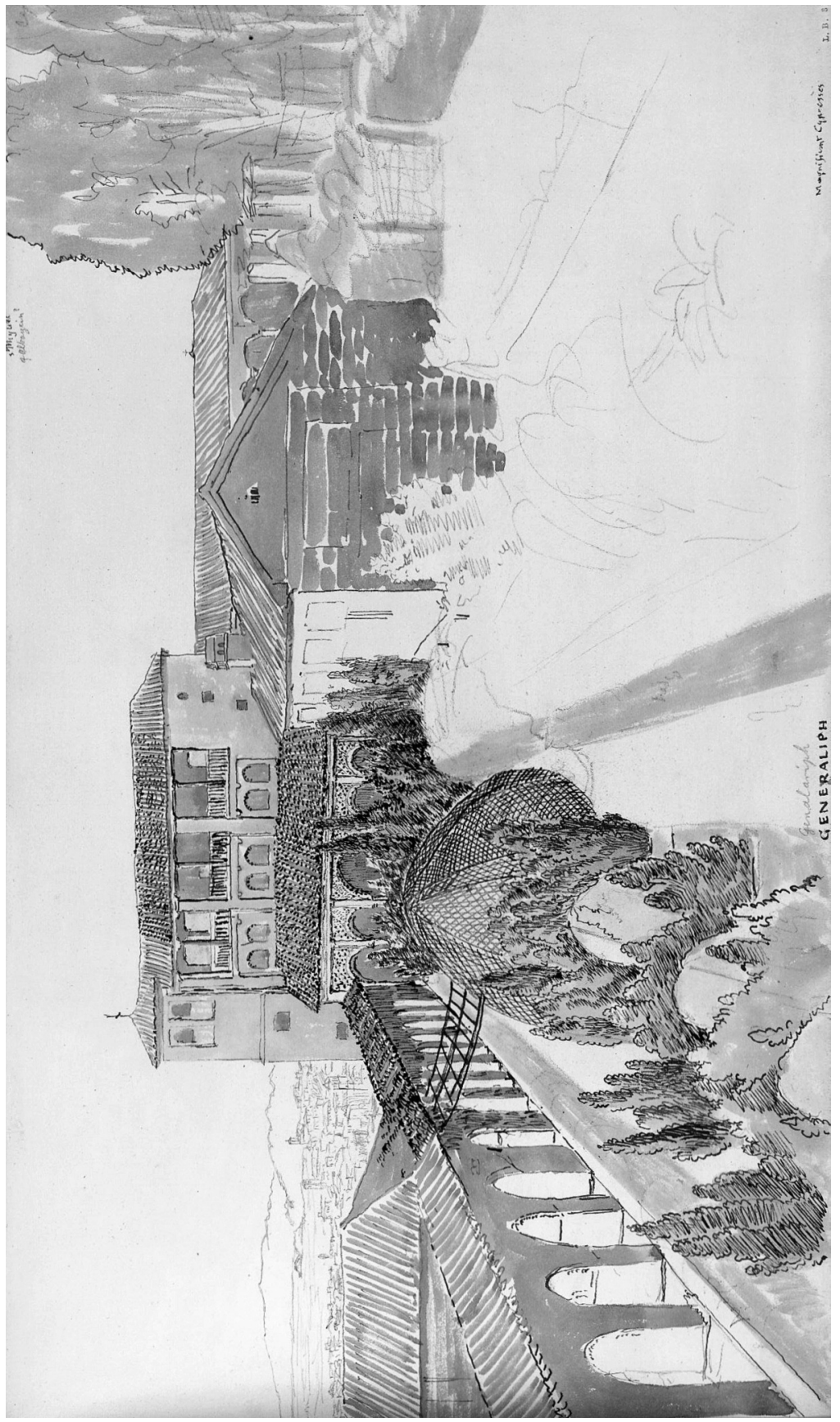

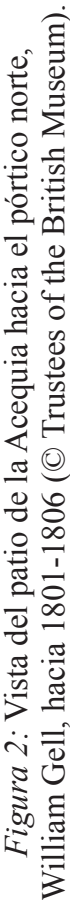

Al-Qanțara XXXV 1, 2014, pp. 29-59 ISSN 0211-3589 doi: 10.3989/alqantara.2014.002 


\section{Bibliografía}

Argote, Simón de, Nuevos paseos históricos, artísticos, económico-políticos, por Granada y sus contornos, Granada, Imprenta de D. Francisco Gómez Espinosa de los Monteros, 1806, 3 vols. Facsímil editado en Granada, Albaida, 1985.

Barrios Aguilera, Manuel, La invención de los libros plúmbeos. Fraude, historia y mito, Granada, EUG, 2011.

Bermúdez López, Jesús et al., La Alhambra y el Generalife. Guía oficial, Granada, TF editores, 2010.

Bermúdez Pareja, Jesús, "El Generalife después del incendio de 1958”, Cuadernos de la Alhambra, 1 (1965), pp. 9-40.

Bigarré, Auguste Julien, Mémoires du General Bigarré, aide de camp du roi Joseph (1775-1813), Paris, Ernest Kolb, 1830.

Blayney, Géneral-Major Lord, Relation d'un voyage forcé en Espagne et en France dans les années 1810 a 1814, Paris, Arthus Bertrand Libraire, 1815, 2 vols.

Bouillé, Louis Marquis de, Souvenirs et fragments (1769-1812), Paris, Kermaingant, 1911, 3 vols.

Calatrava, Juan, "Un retrato de Granada a principios del siglo XIX: los «Nuevos Paseos» de Simón de Argote", Demófilo. Revista de Cultura Tradicional de Andalucía, 35 (2000), pp. 95-110.

Carrasco Urgoiti, María Soledad, “«Paseos» (Juan Velázquez de Echeverría) y «Nuevos paseos por Granada» (Simón de Argote): Haz y envés de un libro guía”, en José Carlos de Torres y Cecilia García Antón (eds.), Estudios de literatura española de los siglos XIX y XX. Homenaje a Juan María Díez Taboada, Madrid, CSIC, 1998, pp. 174-179.

Chateaubriand, François René de, Itinéraire de Paris à Jérusalem, Paris, Gallimard, 2005.

Clemente y Rubio, Simón de Rojas, Ensayo sobre las variedades de la vid común que vegetan en Andalucía, con un índice etimológico y tres listas de plantas en las que se caracterizan varias especies nuevas, Madrid, Imprenta de Villalpando, 1807.

Clemente y Rubio, Simón de Rojas, Viaje a Andalucía. Historia natural del reino de Granada (1804-1809), Barcelona, Griselda Bonet Girabet, 2002.

FARN, Cartas escritas por F. A. R. N. a un amigo suyo, en las que hace reflexiones y reparos sobre varias cosas de los Nuevos Paseos históricos, artísticos, económico-políticos por Granada y sus contornos. Las que pueden servir de suplemento a dichos Paseos; y al mismo tiempo dar luz para hacerse cargo de su mérito, Granada, 1807.

Ford, Richard, Granada. Escritos con dibujos inéditos, Granada, Patronato de la Alhambra y el Generalife, 1955.

García Luján, José Antonio, El Generalife. Jardín del Paraíso, Granada, Copartgraf, 2006. 
García Pulido, Luis José, Análisis evolutivo del territorio de la Alhambra (Granada): el Cerro del Sol en la Antigüedad romana y la Edad Media, (tesis doctoral), Granada, Universidad, 2008.

Giménez-Serrano, José, Manual del artista y del viagero en Granada, Granada, Editor J.A. Lincres, 1846.

Girón López, César, La alcaidía perpetua del Generalife y su pleito: "el pleito del Generalife”, Granada, Caja Granada, 2008.

Gómez-Moreno González, Manuel, Guía de Granada, Granada, Imprenta de Indalecio Ventura, 1892.

Hidalgo Morales, José María, Iliberia o Granada. Memoria histórico-crítica, topográfica, cronológica, política, literaria y eclesiástica de sus antigüedades, desde su fundación hasta nuestros días, Granada, Librería de D. José María Zamora, 1848.

Lafuente Alcántara, Miguel, El libro del viajero en Granada, Madrid, Imprenta D. Luis García, 1849.

López Pérez, Manuel y Lara Martín-Portugués, Isidoro, Entre la guerra y la paz. Jaén (1808-1814), Granada, Universidad, 1993.

López Tabar, Juan, Los famosos traidores. Los afrancesados durante la crisis del Antiguo Régimen (1808-1833), Madrid, Editorial Biblioteca Nueva, 2001.

Malpica Cuello, Antonio, "El complejo hidráulico de los Albercones", Cuadernos de la Alhambra, 27 (1991), pp. 65-101.

Mesmay, General J.T. de, Horace Sébastiani, soldat, diplomate, homme d'Etat, maréchal de France, Paris, H. Champion, 1948.

Miot, André François, Mémoires du Comte Miot de Mélito, Ancien Ministre, Ambassadeur, Conseiller d'État et Membre de l'Institut, Paris, Michel Lévy Frères, 1858, 3 vols.

Orihuela Uzal, Antonio, Casas y palacios nazaries, siglos XIII-XV, Barcelona, Lunwerg-Fundación Legado Andalusí, 1996.

Pavón Maldonado, Basilio, "El Generalife", en Estudios sobre la Alhambra II, Granada, Patronato de la Alhambra, 1977, Anejos de Cuadernos de la Alhambra, 2, pp. 5-19.

Peyron, Jean François, Nouveau voyage en Espagne, Londres, Chez P. Elmsly, 1782.

Puerta Vílchez, José Miguel, Leer la Alhambra. Guía visual del Monumento a través de sus inscripciones, Granada, Edilux, 2010.

Saint-Vincent, Bory de, Guide du Voyageur en Espagne, Paris, Luis Janet, 1823.

Sotomayor y Muro, Manuel, Cultura y picaresca en la Granada de la Ilustración. D. Juan de Flores y Oddouz, Granada, Universidad, 1988.

Tito Rojo, José y Casares Porcel, Manuel, El jardín hispanomusulmán: Los jardines de al-Andalus y su herencia, Granada, Universidad, 2011.

Torres Balbás, Leopoldo, "Dar al-Arusa y las ruinas de palacios y albercas granadinos situados por encima del Generalife”, Al-Andalus, 13 (1948), pp. 185-203. 
Valladar y Serrano, Francisco de Paula, Guía de Granada. Historia, descripciones, artes, costumbres, investigaciones arqueológicas, Granada, Paulino Ventura Traveset, 1906.

Valladar y Serrano, Francisco de Paula, La invasión francesa en Granada (18101812), (compilación de artículos publicados entre 1910-1912), Granada, Ayuntamiento, 2010.

Velázquez de Echeverría, Juan, Paseos por Granada y sus contornos, Granada, Imp. Nicolás Moreno, 1764.

Vílchez Vílchez, Carlos Tomás, El Generalife, Granada, Proyecto Sur, 1991.

Viñes Millet, Cristina, "Documentos sobre el Generalife. Su estado a mitad del siglo XVIII según el reconocimiento general de sitios reales", Cuadernos de la Alhambra, 14 (1978), pp. 99-123.

Recibido: 01/10/2012

Aceptado: 05/03/2013 